\title{
Chapter 7 Specific Skills and Adapted Support
}

\begin{abstract}
Although urban brownfields hold significant inherent potential, especially in limiting urban sprawl, a large number of sites are still awaiting a regeneration project. Moreover, many of these projects only partially or superficially address sustainability principles. Hence, concrete courses of action are required to support the evolution of current practices towards increased sustainability. These courses of action, which rely on specific skills and adapted supports, require a complementary approach. In other words, strategies should be conducted consistently at the territorial, metropolitan, and project levels. In this regard, the present chapter provides a series of courses of action to be implemented at these levels. Our aim here is to foster the sustainable transition of metropolitan areas, and more precisely brownfield sites, into lively neighbourhoods.
\end{abstract}

Keywords Urban brownfield regeneration - Sustainable transition of European metropolitan areas $\cdot$ Evolution of current practices $\cdot$ Increased sustainability • Territorial strategies $\cdot$ Metropolitan strategies $\cdot$ Project strategies

\subsection{Courses of Action to Support the Evolution of Current Practices}

When observing brownfields in European metropolitan areas, we must stress that the majority of them are not in the process of regenerating. Moreover, many redevelopment operations only partially or superficially address sustainability principles. Due to their adverse impacts on environmental, sociocultural, and economic levels, the issue of brownfields is not only well understood at the European level but also ranked high on the agenda of European Union regional development, environmental protection, and urban initiatives (Franz et al. 2006).

In this context, the different concerned stakeholders must converge to a series of measures and more concrete courses of action to support the evolution of current practices towards increased sustainability. In a complementary approach, these actions should be conducted consistently not only at the territorial levels of the metropolitan area, urban region, and municipality but also at the urban and architectural levels, embodied in the neighbourhood scale of the regeneration project itself. In this regard, 
the present chapter provides strategies at different levels to develop courses of action involving specific skills and adapted support.

\subsection{Strategies at the Territorial Level}

First, three main courses of action can be identified at the level of public authorities in charge of territorial development at the national or regional scales. It should be specified that some of these strategies already (partially) exist in certain European countries.

\subsubsection{Awareness of Urban Brownfield Potential}

The first course of action focuses on raising awareness of urban brownfields' potential (see Chap. 3). The main objective is to modify the general perception of brownfields and to make stakeholders more aware of their potential to increase the sustainability of European metropolitan areas. Several professional urban planning networks have been developed in the past, such as CABERNET or RESCUE, but it is essential that exchanges of that type also be created or reinforced with non-specialists.

Just like with other challenges related to the densification of built fabric, urban brownfields' potential is not automatically perceived by all political and economic decision-makers. Among the various possible measures to improve this situation, we can cite:

- developing communication campaigns (publications, public conferences, dissemination in the media, etc.);

- valorizing exemplary projects in terms of sustainability integration, stressing, in particular, their compatibility with economic success (pilot projects, awards, etc.);

- organizing meetings between brownfield landowners and potential investors;

- raising awareness of sustainable development issues within structures in charge of the real estate management of large urban brownfield landowners, in particular armies and railway companies.

In parallel, it is highly important that quantitative monitoring of an urban brownfield be generalized in European countries, with a detailed and regularly updated inventory. As explained earlier, the lack of data about brownfields tends to prevent an objective picture of the phenomenon or even to minimize its importance (Rey and Lufkin 2015). 


\subsubsection{Evolution of the Legal Framework}

The second course of action aims at creating a legal framework that supports the launching of brownfield regeneration operations. Keeping in mind that obstacles to redeveloping abandoned sites concern primarily the initial, start-up phase of the project, improving the framework in the early stages helps mitigate blockages and fosters the emergence of project dynamics. Diverse forms of impulse may exist:

- integrating one or more specific articles focusing on urban brownfield regeneration in territorial planning regulations (in particular to enable procedures facilitating land-use change and the project's start-up);

- explicitly mentioning urban brownfield regeneration as a strategic objective of territorial development policies;

- promoting a general territorial organization of dense, mixed-use polarities, coordinated at the national or regional scales, which will help actors anticipate the evolution of urban brownfields' regulatory status and react more rapidly to the evolution of needs (exogenous economic promotion, housing stock to anticipate the risk of shortages, etc.).

In order to overcome obstacles related to remediation costs, it also seems appropriate to implement financial support for the investigation and remediation of contaminated sites. A possible measure is the creation of specific funds managed at the national level, made up of part of the increased value of land generated by brownfield regeneration. This mechanism offers landowners the advantage of removing uncertainty regarding their site's contamination, focus initial investments on the project itself and refund certain expenses once the redevelopment is guaranteed (risk reduction).

\subsubsection{Development of Financial Levers}

The third course of action, probably one of the most efficient, focuses on the development of financial levers, which support—directly or indirectly_urban brownfield regeneration and, more broadly, the densification of built fabrics. Today, it is not necessarily more interesting for a real estate stakeholder to invest in an urban site than a peripheral one. Tax mechanisms, which tend to be impacted by strong competition between municipalities, do not really reflect costs generated by peri-urban development and may not adequately reflect the potential brownfield regeneration has for contributing to the general interest. In Great Britain, the president of the Royal Town Planning Institute summarized this situation by declaring that urban planners were asked to fight the battle of sustainable development without any weapon (cited in Fouchier 1997).

The better orientation of certain fiscal or regulatory modalities for sites redeveloped in a sustainability perspective may also help accelerate the regeneration 
of urban brownfields. As examples, we can cite improving financial equalization between municipalities of an urban or metropolitan area, adapting certain taxes for urban brownfields or implementing premia for higher densities, which may allow for a better valorization of the land.

Support for exemplary projects in terms of sustainability, as well as targeting certain subsidies specially attributed to this kind of project, may also help consolidate the most interesting approaches. Considering their strategic importance, some urban brownfield regeneration operations could benefit from specific financial supports. As an example, we can cite the case of the German North Rhine-Westphalia, who, since 1997, only subsidizes housing located near train stations or efficient public transport_-including housing created on regenerated urban brownfield sites. Besides density and sustainable mobility, the next step would be to consider additional criteria related to environmental, sociocultural, and economic sustainability in the calculation of the financial supports to be attributed.

\subsection{Strategies at the Metropolitan Level}

To amplify their impact, the three above-described territorial courses of action should be relayed at the metropolitan and city levels, which requires active participation by public entities and, especially, increased inter-municipal collaboration. Indeed, the development of urbanization and the complexity of post-industrial European cities tend to explode the traditional limits of municipal management. Moreover, it appears that collaboration is necessary at an inter-municipal level. It implies the emergence of novel types of governance, which are capable of managing metropolitan or conurbation projects and pooling converging visions of territorial development.

\subsubsection{Integration of Urban Brownfield Regeneration Projects Within Urban Planning Tools}

The first course of action at the metropolitan level focuses on increased integration of urban brownfield regeneration projects within urban planning tools, in particular metropolitan or conurbation projects, which help overcome inter-municipalityrelated obstacles. This type of approach seems likely to strongly impact the localization of urban activities, limit peripheral constructions based on public transport systems, support the densification of already built-up areas, and efficiently meet the various sociocultural needs of metropolitan areas.

Considering its potential contribution to the built environment's sustainability, urban brownfield regeneration — in particular, that of large sites_-should be included 
in the issues to be examined within metropolitan or conurbation projects. This embedding will help multiply their chance of redevelopment. By integrating urban brownfields into a vision that goes beyond the limits of their perimeter, it is indeed possible to increase opportunities for convergence between needs-considered at metropolitan scale_-and land available for new (re)development.

\subsubsection{Identification of Strategic Sectors for Urban Development}

In parallel, the embedding of urban brownfields within metropolitan or conurbation projects should lead to a finer census of the latter, integrating specific information such as the degree of proximity to public transport systems, effective densification possibilities, possible land-use changes, and funding possibilities for a regeneration project. As illustrated in Chap. 3, this type of analytical inventory is far from systematic among European countries, which sometimes makes it difficult to identify the most strategic sectors to be redeveloped.

However, the identification of an abandoned site as a pole of strategic development is not sufficient to guarantee the spontaneous start of its regeneration process. In some cases, the site has real estate potential, but may eventually redevelop without integrating broader issues related to needs at the metropolitan level or sustainability aspects. In other cases, the site is strategic for the sustainable transition of the metropolitan area but struggles to find investors.

Therefore, it is fundamental that the dialogue between partners from the public and private sectors be intensified, and all the more so when land is privately owned. Collaboration in the early stages of the regeneration process helps to target the most important aspects, concretely discuss framework conditions, and potentially accelerate the procedure by anticipating any risk of blockage. According to the site's features and the circumstances surrounding the project launch, the objective will be to find a tailored strategy to best accommodate the general interest and financial constraints.

This proactive involvement of public authorities becomes even more essential because their means are often limited to buying land or investing directly in regeneration projects. Even if the public authority does not own the land, it can, by collaborating with private stakeholders, take advantage of certain dynamics all while materializing sustainability-related objectives such as densification, functional mix and social diversity, sustainable mobility, or the emergence of an urbanity fostering a high quality of life.

By benefitting from room to manoeuvre (such as density bonuses or adaptations of some equipment taxes), public authorities and concerned services may even obtain the guarantee of a stricter follow-up of all sustainability dimensions of the project, for instance by requiring more explicitly the use of a monitoring methodology (more on monitoring in Chap. 8). 


\subsection{Strategies at the Project Level}

Finally, specific measures taken at the project level are necessary not only to make the start-up of a sustainable regeneration project possible but also to ensure that the future neighbourhood contributes to the sustainability transition of the city and metropolitan area. In that regard, we identify four main courses of action.

\subsubsection{Initiation and Governance of Regeneration Project}

In order to make the start-up of a sustainable regeneration project possible, the initiation of the operation and the emergence of the project dynamic are crucial measures. The initiation of the operation is based on a process likely to play a triggering role. It mainly results from two types of approaches, according to the site's characteristics and involved stakeholders:

- the organization of urban planning or architecture competition by the landowner (generally in collaboration with the concerned public authority);

- the realization of a test study or a project, either mandated by the landowner or a potentially interested investor, or on the spontaneous initiative of an urban planning or architecture office.

The different triggering possibilities demonstrate that the process is generally based on shared responsibility between different stakeholders (landowners, public authorities, project designers, investors, etc.). The initiation of the process depends on the efficiency of their collaboration. The landlord has the possibility to block the process, and therefore certainly plays a crucial role in this initial phase.

Subsequently, the emergence of the project dynamic corresponds to the consolidation of this first stage. In other words, the objective is to effectively integrate all involved partners within the approach to a project - rather than within the vision for an abandoned site. Our analysis of several large-scale regeneration projects across European metropolitan areas stresses that the creation of a project dynamic is most commonly related to the emergence of the main stakeholder, who plays the driving role for the project.

The main stakeholder may come from diverse professional backgrounds, considering the multiple possibilities a project represents. Our study of different operations highlights that architects and urban planners have a certain propensity to play that driving role, as long as they have the capacity to perceive a site's potential, motivate other actors to support the project, and coordinate complex processes or even conduct mediation when interests diverge or the risk of blockage appears. This observation results in the need to raise awareness of the importance of this skill set, not only among architecture and urban planning students but also among the concerned professional associations. 


\subsubsection{Integration of Sustainability Objectives}

Moreover, the recognition and integration of sustainability objectives in the project dynamics are essential conditions for their materialization. To be effective, this integration should be translated into the implementation of a holistic, inter-disciplinary, and evaluative approach, under the auspices of the main stakeholder playing the driving role. Indeed, the success of an operational evaluation depends, first and foremost, on the effective motivation of the involved actors-in particular the decisionmakers (public and/or private clients) — to apply sustainability principles. Based on a selection of relevant indicators, the operational evaluation helps to structure the project's objectives and implement a consistent monitoring methodology.

The project's transition towards increased sustainability involves implementing participative and inter-disciplinary collaborations, which should be consistently integrated within the project. For the project leader, this requires, by definition, a great capacity to integrate data from heterogeneous sectors, coordinate actors with diverse references and knowledge, and identify future necessary competencies. For all important stakeholders involved in the project, this entails increased competencies in the field of sustainable development, allowing them to establish links between the variety of dimensions at stake.

\subsubsection{Follow-Up of Sustainability Objectives}

According to the project's characteristics, two main scenarios are possible for identifying the person responsible for the evaluation, the major condition is that the entity in charge of the project supports the selected process.

- In the first scenario, the project's driver (for instance, the public authority's urban planning department) directly steers the evaluation, motivated by integrating sustainability within the project. This option tends to facilitate the process and allows for continuous optimization. The risk of subjective evaluation can be limited by constituting a follow-up group including different interests (representatives of the authorities, the client, etc.).

- The second scenario consists of selecting an external expert to steer the evaluation. This situation may ensure greater independence in the evaluation process. However, it poses the risk of creating a gap between the evaluation results and the project development. This may be avoided by implementing a tight collaboration between the external expert and the project's driver, which may generate a more unwieldy and costly process. This type of approach may be recommended, in particular, when the project's driver lacks competences or motivation-or both—with regard to sustainability.

In both scenarios, a follow-up group must be created to regularly accompany the project's evolution and its operational evaluation during specific meetings (as a 
rule, every 3-6 months). The project's usual coordination meetings then help address the concrete integration of the measures adopted. In that sense, creating a specific framework for discussion relating to sustainability seems to encourage the emergence of an adhesion and ripple effect among the different involved stakeholders.

The implementation of a sustainability follow-up-or more precisely monitoring (see Chap. 8) - necessarily generates additional costs compared to current planning expenditures. The latter should, however, be weighed against the operation's global cost, especially since this approach results in most cases in buildings of superior overall quality. The long-term benefits induced by the increases in the properties' real estate value often outweigh the additional costs incurred (Chegut et al. 2019). Based on our analysis of brownfield regeneration projects into sustainable neighbourhoods, the specific cost of sustainability monitoring and data synthesis is estimated at approximately $0.5 \%$ of the operation's global cost (Rey 2012).

Several measures can be envisaged to decrease the additional financial load of sustainability monitoring. Without going into too much operational detail, we can cite the following measures: using part of the increase in the land value generated by the regeneration operation, receiving financial contributions from programmes supporting exemplary projects, and collecting a specific percentage of the total construction costs.

\subsubsection{User Awareness}

The commissioning of an urban brownfield regeneration project is usually conducted on a step-by-step basis. It generally implies an information process for the neighbourhood's users, who will live or work for several years within a changing urban environment. Communications made in this context may also provide an opportunity to raise user awareness of specific aspects of sustainability, especially those significantly conditioned by user behaviour (such as the consumption of heat, electricity, or drinking water). This approach targeting user awareness helps to inform users of the intentions of the project's designers, as well as facilitate their appropriation thereof.

\section{References}

Chegut A, Eichholtz P, Kok N (2019) The price of innovation: an analysis of the marginal cost of green buildings. J Environ Econ Manag 98:102248. https://doi.org/10.1016/j.jeem.2019.07.003

Fouchier V (1997) Les densités urbaines et le développement durable, le cas de l'Ile-de-France et des villes nouvelles. Editions du SGVN, Paris

Franz M, Pahlen G, Nathanail P et al (2006) Sustainable development and brownfield regeneration. What defines the quality of derelict land recycling? Environ Sci 3:135-151. https://doi.org/10. 1080/15693430600800873 
Rey E (2012) Régénération des friches urbaines et développement durable: vers une évaluation intégrée à la dynamique du projet. Presses Universitaires de Louvain, Louvain-La-Neuve

Rey E, Lufkin S (2015) Des friches urbaines aux quartiers durables. Presses polytechniques et universitaires romandes, Lausanne

Open Access This chapter is licensed under the terms of the Creative Commons Attribution 4.0 International License (http://creativecommons.org/licenses/by/4.0/), which permits use, sharing, adaptation, distribution and reproduction in any medium or format, as long as you give appropriate credit to the original author(s) and the source, provide a link to the Creative Commons license and indicate if changes were made.

The images or other third party material in this chapter are included in the chapter's Creative Commons license, unless indicated otherwise in a credit line to the material. If material is not included in the chapter's Creative Commons license and your intended use is not permitted by statutory regulation or exceeds the permitted use, you will need to obtain permission directly from the copyright holder.

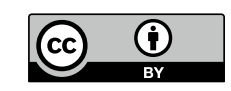

